\title{
Social Sciences, Bioethics, and the Question of Population
}

\author{
Anindita Majumdar ${ }^{1} \cdot$ Paro Mishra $^{2} \cdot$ Ravinder Kaur $^{3}$ \\ Published online: 15 January 2021 \\ (C) National University of Singapore and Springer Nature Singapore Pte Ltd. 2021
}

The deep interconnections between biology, population politics, and ethics have been strongly brought to the fore by the ongoing COVID-19 pandemic. The virus has highlighted the ways in which governments and state machineries calculate, control, and manage entire populations and demographic groupings, akin to what Foucault refers to as 'biopolitics' (Burchell et al. 1991): through measures such as complete or partial lockdowns, contact tracing, clinical trials, and vaccination. These steps immediately raise several important ethical concerns around questions of discrimination, inequality, surveillance, security, privacy, right to healthcare, and social protection. In this special issue, we foreground the discussion of bioethics in relation to demography and population politics by focusing on the two most populous countries in the world, India and China. In the process, we seek to enhance our understanding of the ways in which biology is enmeshed with population politics and the nature of bioethical concerns this generates. In doing this, we are guided by the conceptualisation that population as bioresource is not only 'bioavailable' (Cohen 2007) but can be rendered into 'biocapital' as Rajan (2006) articulates in his study of clinical trial patients.

As the most populous countries in the world, India and China have come to mark our collective conscience in significant ways (Eklund and Purewal 2017; Kaur 2020). The stance has, however, shifted considerably from fears of overpopulation and high fertility rates, to policies encouraging childbearing and addressing infertility through assisted reproduction. As a superpower, China is interested in facilitating birth amongst a chosen few; while India continues with its ambivalent posture on the domestic use of in vitro fertilization and other reproductive technologies, prohibiting the transnational traffic of 'unsuitable foreigners' and 'non-heteronormative families' to avail of the

Anindita Majumdar

anindita@la.iith.ac.in

1 Department of Liberal Arts, Indian Institute of Technology Hyderabad, Kandi, India

2 Department of Social Sciences and Humanities, Indraprastha Institute of Information Technology Delhi, New Delhi, India

3 Department of Humanities and Social Sciences, Indian Institute of Technology Delhi, New Delhi, India 
same. Most importantly, by aggressively participating in regulating the use of these technologies, the Indian and Chinese states are also keenly redefining the intimate lives of their citizenry. This is seen most pointedly in the recent change in the one-child policy of the Chinese state, and the newly drafted Indian Surrogacy Bill (soon to be an Act). In China, there are fears of environmental and industrial pollution leading to a diminution in sperm quality (Wahlberg 2018); in India, ethnically varying fertility transitions are deployed to further religious and political agendas (Chatterjee and Riley 2001; Singh 2020); globally, there is the spectre of 'surplus' men and 'scarce' women in rising Asia (John et al. 2008; Hudson and den Boer 2004; Kaur 2018; Purewal 2016). Additionally, with crucial generational shifts posing a threat to the earlier stability of marriage and child-centeredness, reproduction and reproductive processes are provoking yet newer moral and cultural anxieties. Resulting familial, kinship, and policy shifts are paramount in the ways in which China and India are approaching reproductive technologies and demographic transformation. Here, cultural peculiarities are beginning to provide new forms of engagement with the decade-long state, research, and policy obsessions with population control. There is little doubt that we need newer and more nuanced research paradigms than the ones informed by earlier understandings of population rhetoric. We need to understand the emerging familial configurations of third-party donor families facilitated through IVF, commercial surrogacy, and bride-shortage-related marriage migration and inter-generational care deficit among the many other social phenomena that are resulting from newer demographic trends.

The papers presented in this special issue emerged from a conference on 'Reproduction, Demography and Cultural Anxieties in India and China in the $21^{\text {st }}$ Century' held at New Delhi, India, in February 2020. The contributors reflect on the value of ethics and ethical practices in relation to biological issues of demographic transformations and changing reproductive landscapes in the emergence of New Reproductive Technologies (NRTs). We further the discussions at the conference through three primary focus areas.

a. The Social Sciences in Conversation with Bioethics: This special issue is firmly embedded in a social science focus that aims to reflect upon bioethics from the vantage point of how social practices intermingle with reproductive practices and technology in China and India. Here, the arguments and structure of the research papers highlight the need for greater engagement between society and medicine, especially medical technologies that have far-reaching consequences for people and populations. Thus, the special issue sheds light on practices and processes that may be offshoots of technological interventions into bodies and biologies: such as sex selective abortions and assisted reproduction.

b. Reproductive Technologies and Bioethics: The focus on reproduction and reproductive technologies helps hone our discussion on bioethics and how it can be framed in terms of socio-medical practices and ideas, especially in the Global South where changing ideas regarding demography and population are spearheading medical innovations. Thus, 'selective reproductive technologies' (Wahlberg and Gammeltoft 2018) such as conceptive technologies, sex selection, and assisted reproductive technologies (ART) (for instance IVF) bring to the fore emerging questions of bioethical inquiry in relation to 'population management' 
(Brunson 2016; Chatterjee and Riley 2001; Gammeltoft 2014; Greenhalgh 2008; Murphy 2012; Wahlberg 2018). The special issue broadens the scope of looking at reproductive technologies to spheres of operation including changes in demographic culture and character through female-selective abortions, or pursuing preconception selection (the technological intervention into 'designing' a foetus to be of a particular sex, racial, and other characteristics).

c. Social Demography and Bioethical Questions: One of our innovative approaches in this special issue brings together research linking bioethics to social practices such as marriage, family making, care provision, legal injunctions, and state policies. The focus is on how populations and demographic predictions are intimately intertwined with state policies regarding reproduction and reproductive technologies, such as family planning, surrogacy, assisted reproductive technologies, and sex selective abortions. Such state interventions happen through law and policies at one level and at another through the mapping of emerging social practices involving family making and marriage. Marriage (or the lack of it) is an important subtext to some of the papers in the issue, reflecting upon the ways in which reproduction and procreation not only remain an important goal of socially mandated intimacy but also become a vehicle for social reproduction of individuals, families, and communities. The questions we are asking here interrogate the forms of interventions that communities and states undertake in 'fashioning' populations through particular social practices.

These three vantage points come together in Bhatia's (2021), Majumdar's (2021), and Weis's (2021) papers on reproductive technologies and the reconfiguring of populations through specific biological markers. In Bhatia's (2021) paper, China and India are situated within the globally stratified landscape of sex selection through ARTs, challenging the understanding of sex selection as 'unethical' in some societies and as 'choice' in other societies. She examines this practice as a part of a 'global form' of family balancing and construction of a particular 'lifestyle' in some Western countries, being dubbed as patently unethical in other non-Western countries where sex selection happens in the context of son preference and state anti-natalist policies. Majumdar (2021) presents (un)ethical underpinnings of the ways in which ARTs are used by medical practitioners in India to circumvent the 'biological clock' and 'manage' declining reproduction of female bodies, young and old. The intrusive technomedical approach, with its exclusive focus on eggs and wombs, and a rhetoric of 'decline' and viable pregnancy not only disaggregates women's bodies into parts but also erases the possibility of any engagement with women's agency and choice. The question of choice and ethics is also central in Weis's (2021) examination of crossborder fertility landscapes between China and Russia. Here, Chinese fertility travellers are actively appropriating ARTs to 'fashion' progeny by either creating phenotypical resemblance in them by using Asian donors or by selecting 'white' donors to engineer 'enhanced', 'superior' children, thereby fuelling racialized imaginaries and exacerbating inherent inequalities in global reproductive care chains.

Are certain populations compromised in the practice and social potency surrounding reproductive technologies? One of the questions we are examining through a bioethical lens is centred on the identification of emerging demographies as 'residues' of sex selection and assisted reproduction. By 'residues', we are keen to understand how 
certain sets of age and gender demographies are threatened into forms of social debility due to certain biotechnological processes. Thus, in Mishra's (2021) paper, adult unmarried sons and their debilitated ageing parents have become threatened as a result of new forms of bioregimes that have eliminated female foetuses in the protection and pursuit of male babies in north India, creating bride-shortages, complicating and shifting local ethics of care within the family-household. In Meng et al.'s (2021) paper, foetal sex-determination technology and sex-selective abortions have put ageing bachelors - alone through no choice of their own - at a heightened risk of having less or no familial care. This is caused by a conflict between the individual's family life and societal family ethics. The inability to marry becomes a trope of the ways in which certain populations become liabilities for those nation states and communities that are actively involved in 'designing' desired families, and by extension, populations. Similarly, Gu (2021) shows how unmarried women become part of a population marked by the imaginings around pronatalism and the biological clock. Gender is a very important marker of bioethics here, both in how it is manufactured socially and marked physiologically through pronatalist conversations around suitable progeny.

In our final paper, population itself is the biocapital, which is valued through its demographic returns. In Kaur and Kapoor's (2021) paper, populations move and change not only through identified processes of demographic movement, but through concerted and orchestrated social processes wherein genders become valued as commodities to be invested in, and or harvested, raising questions of gender justice. The use of sex selection technologies to eliminate girls is constructed as rational and scientific (and hence ethical) while being enmeshed in state policies and family biosocial strategies of social mobility. This final paper concludes the discussion that the previous papers began to look at, viz. the imaginings around populations: whether through 'restrained natalism' as Wahlberg (2019) calls it, in the case of China, or through investment in women and girl children, to rethink sex ratio imbalances in India. Here, bioethics is part of real-time community, state, and individual investments into thinking about the future of social demographics.

\section{References}

Bhatia, Rajani. 2021. Figuring India and China in the constitution of globally stratified sex selection. Asian Bioethics Review 13 (1). https://doi.org/10.1007/s41649-020-00160-0.

Brunson. 2016. Planning families in Nepal: global and local projects of reproduction. Brunswick: Rutgers University Press.

Burchell, Graham, Colin Gordon, and Peter Miller, eds. 1991. The Foucault effect: studies in governmentality. Chicago: University of Chicago Press.

Chatterjee, Nilanjana, and Nancy E. Riley. 2001. Planning an Indian modernity: the gendered politics of fertility control. Signs: Journal of Women in Culture and Society 26 (3): 811-845. https://doi.org/10. $1086 / 495629$.

Cohen, Lawrence. 2007. Operability, bioavailability, and exception. In Global assemblages: technology, politics, and ethics as anthropological problems, ed. Aihwa Ong and Stephen J. Collier, 79-90. Malden: Blackwell Publishing.

Eklund, Lisa, and Navtej K. Purewal. 2017. The bio-politics of population control and sex-selective abortion in China and India. Feminism \& Psychology 27 (1): 34-55. https://doi.org/10.1177/0959353516682262.

Gammeltoft, Tine M. 2014. Haunting images: a cultural account of selective reproduction in Vietnam. Berkeley: University of California Press. 
Greenhalgh, Susan. 2008. Just one child: science and policy in Deng's China. Berkeley: University of California Press.

$\mathrm{Gu}$, Xiaorong. 2021. 'You are not young anymore!': gender, age and the politics of reproduction in postreform China. Asian Bioethics Review 13 (1). https://doi.org/10.1007/s41649-020-00157-9.

Hudson, Valerie M., and Andrea den Boer. 2004. Bare branches: the security implications of Asia's surplus male population. Cambridge: MIT Press.

John, Mary E., Ravinder Kaur, Rajni Palriwala, Saraswati Raju, and Alpana Sagar. 2008. Planning families, planning gender: the adverse child sex ratio in selected districts of Madhya Pradesh, Rajasthan, Himachal Pradesh, Haryana and Punjab. New Delhi: ActionAid.

Kaur, Ravinder, ed. 2018. Too many men, too few women: social consequences of gender imbalance in India and China. New Delhi: Orient BlackSwan.

Kaur, Ravinder. 2020. Gender and demography in Asia (India and China). In Oxford Research Encyclopedia of Asian History. https:/oxfordre.com/asianhistory/view/10.1093/acrefore/9780190277727.001.0001/ acrefore-9780190277727-e-345. Accessed 13 December 2020.

Kaur, Ravinder, and Taanya Kapoor. 2021. The gendered biopolitics of sex selection in India: increasing the 'bio-value' of daughters. Asian Bioethics Review 13 (1). https://doi.org/10.1007/s41649-020-00159-7.

Majumdar, Anindita. 2021. Ageing and reproductive decline in assisted reproductive technologies in India: mapping the 'management' of eggs and wombs. Asian Bioethics Review 13 (1). https://doi.org/10.1007/ s41649-020-00161-z.

Meng, Yang, Bo Yang, Shuzhuo Li, and Marcus W. Feldman. 2021. Marriage, health and old-age support: risk to rural involuntary bachelors' family development in contemporary China. Asian Bioethics Review 13 (1). https://doi.org/10.1007/s41649-020-00163-x.

Mishra, Paro. 2021. Reproductive technologies, care-crisis and inter-generational relations in North India: towards a local ethics of care. Asian Bioethics Review 13 (1). https://doi.org/10.1007/s41649-020-001588.

Murphy, Michelle. 2012. Seizing the means of reproduction: entanglements of feminism, health, and technoscience. Durham: Duke University Press.

Purewal, Navtej K. 2016. Son preference: sex selection, gender and culture in South Asia. Abingdon: Routledge.

Rajan, Kaushik Sunder. 2006. Biocapital: the constitution of postgenomic life. Durham: Duke University Press.

Singh, Holly Donahue. 2020. Numbering others: religious demography, identity, and fertility management experiences in contemporary India. Social Science \& Medicine 254: 112534. https://doi.org/10.1016/j. socscimed.2019.112534.

Wahlberg, Ayo. 2018. Good quality: the routinization of sperm banking in China. Berkeley: University of California Press.

Wahlberg, Ayo. 2019. Restrained natalism - from family planning to family making in China and East Asia. Paper presented at the EastAsiaNet Workshop, Asian Dynamics Initiative, University of Copenhagen, 2527 April 2019.

Wahlberg, Ayo, and Tine M. Gammeltoft. 2018. Selective reproduction in the $21^{\text {st }}$ century. London: Palgrave Macmillan.

Weis, Christina. 2021. Changing fertility landscapes: exploring the reproductive routes and choices of fertility patients from China for assisted reproduction in Russia. Asian Bioethics Review 13 (1). https://doi.org/10. 1007/s41649-020-00156-w.

Publisher's Note Springer Nature remains neutral with regard to jurisdictional claims in published maps and institutional affiliations. 